DOI:10.29252/ijn.32.122.41

Iran Journal of Nursing (IJN)

Vol 32, No. 122, Feb 2020: 41- 54

\title{
The Attitude and Performance of Nurses Regarding Pain Management in the Patients Admitted to the Emergency Department
}

\author{
Jaleh Mohammad Aliha ${ }^{1}$, Tahereh Najafi Ghezeljeh ${ }^{2}$, Shima Haghani ${ }^{3}$ \\ Shirin Nasrollah Nejhad ${ }^{4}$
}

\begin{abstract}
Background \& Aims: Pain management is an integral part of patient care in emergency departments. Nurses play a key role in the pain management of patients, and all patients deserve to be free of pain. One of the biggest challenges in nursing is ensuring patients' comfort and lack of pain. Not only effective pain relief in patients results in their physical comfort but also increases their quality of life and rapid return to daily life and decreases their hospital stay duration and costs. Nurses are the first people present at the patient's bedside during pain and have the longest stay with the patient. Therefore, the most successful nurses are those who have competence in assessing pain. Nurses are required to make timely decisions in the dynamic and changing situation of clients by using technical skills and professional knowledge. In addition, they must make a proper clinical judgment about patients' health status through acquiring basic information about clients, determining natural and unnatural functions and abilities of clients, and using proper information. Positive attitude and proper performance of health care providers towards pain management is very important and is part of patients' rights. Therefore, the present study aimed to determine the knowledge of nurses regarding pain management in the patient referring to the emergency departments of the hospitals.

Materials \& Methods: This descriptive, cross-sectional study was conducted on 150 emergency department nurses selected via census sampling in the hospitals affiliated to Iran University of Medical Sciences in 2018. The inclusion criteria were the minimum education level of master's degree and six months of work experience in the emergency department. Data were collected using the demographic questionnaire (included six items to determine the demographic characteristics of nurses such as age, gender, level of education, type of hospital, and work experience) and the questionnaire of knowledge of pain management (included 20 items), in which the responses of the participants determined their attitude toward the use of narcotics, the person responsible for pain control and use of nonpharmaceutical interventions). The items were scored based on a four-point Likert scale from completely agree (four scores) to completely disagree (one score). In addition, the score range of the instrument was 35-62, where a score above $62 \%$, between $35 \%$ and $62 \%$, and below $35 \%$ was indicative of positive, moderate and negative attitude, respectively. The construct validity of the tool was assessed by comparing the scores of experienced and skilled nurses, which demonstrated a difference in the expertise of different groups. On the other hand, the performance questionnaire encompassed four items on patients' pain level and type, analgesics and one item on the tools applied to measure pain (the name of the tool used to measure pain). The tool was completed by nurses (through self-report) and the scores were $0-2(0=$ no, $1=$ to some extent, and $2=y e s)$. In the end, the performance score was obtained, where the lowest and highest scores were zero and eight, respectively. In this respect, a score higher than the median (i.e., four) indicated good performance, whereas a score below the median demonstrated poor performance. Data analysis was performed

1. Lecturer, School of Nursing and Midwifery, Iran University of Medical Sciences, Tehran, Iran

2. Associate Professor, Nursing Care Research Center, School of Nursing and Midwifery, Iran University of Medical Sciences, Tehran, Iran

3. MS in Biostatistics, Nursing Care Research Center, Iran University of Medical Sciences, Tehran, Iran

4. MS, Shohada-e Haftom-e Tir Hospital, Iran University of Medical Sciences, Tehran, Iran (Corresponding author)

Tel: 09305803335 Email: nasrolahnejhad.sh@iums.ac.ir
\end{abstract}


in SPSS version 16 using descriptive statistics (frequency tables, mean, and standard deviation) and inferential statistics (Pearson's correlation coefficient).

Results: Mean age of the participants was $31.98 \pm 5.52$ years. The majority of the nurses $(82.9 \%)$ had no prior experience of pain management training. Regarding pain management in the emergency department, $82.7 \%$ of the subjects had a moderate attitude (35-62 scores) while $17.3 \%$ had a positive attitude and no subject had a negative attitude. Moreover, the mean attitude score was reported to be $57.16 \pm 5.22$, and the mean and standard deviation of performance was $6.02 \pm 2.53$, which was higher than the median score of the tool. The results indicated no significant difference between the mean scores of attitude and performance with the demographic characteristics of the participants $(\mathrm{P}>0.05)$.

Conclusion: According to the results, the emergency department nurses had a moderate knowledge level regarding pain management. In addition, they declared proper performance in this regard. Nevertheless, they had insufficient knowledge of pain tools and their method of use. The findings of the present study showed that although the nurses stated that they had good performance and knowledge about the importance of recording and controlling pain, it seems that the necessity of completing the initial assessment form caused nurses to repeat and practice how to complete the form. In this respect, the forms demonstrated better performance of nurses while they had insufficient knowledge of the tools. Therefore, the provision of periodic training and pain assessment facilities and the implementation of proper policies and methods for pain assessment could be effective in this regard. In addition, the performance of nurses in managing patients' pain in the present study was indicated through a self-report questionnaire. As such, it is recommended that the performance of nurses be assessed through observation. It is also suggested that pain management by nurses in emergency departments be assessed from the viewpoint of patients and the effect of pain management education on the knowledge and performance of nurses.

Keywords: Attitude, Performance, Pain Management, Emergency

\section{Conflict of Interest: No}

How to Cite: Mohammad Aliha J, Najafi Ghezeljeh T, Haghani SH, Nasrollah Nejhad SH. The Attitude and Performance of Nurses Regarding Pain Management in the Patients Admitted to the Emergency Department. Iran Journal of Nursing. 2020; 32(122):41-54.

Received: 11 Nov 2019

Accepted: 8 Feb 2020 


\title{
نكر ش و عملكر د ير ستاران در رابطه با مديريت درد بيماران در بخشهاى اورزانس
}

\author{
زاله محمد عليها'، طاهره نجفى قزلجه '، شيما حقانى بّ، شيرين نصر الله نزادع
}

زمينه و هدف: مديده ئ هديت درد يكى از مهمترين اجزاى مراقبت درد بيماران در بخش اورزانس است و برستار نقش كليدى در مديريت درد دارد. نكرش مثبت

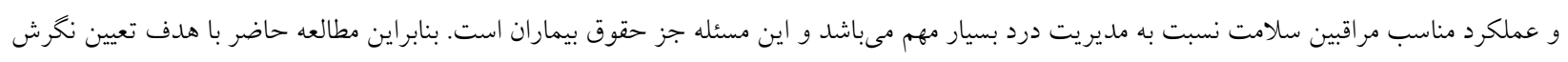

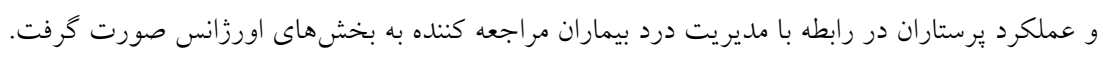

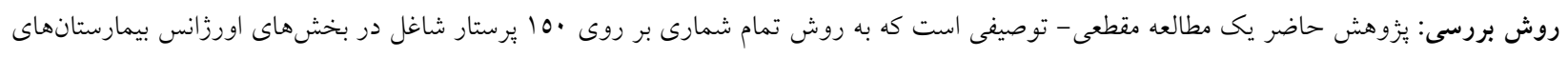

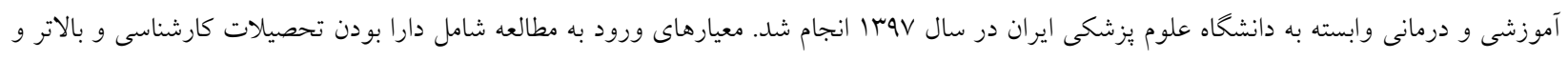

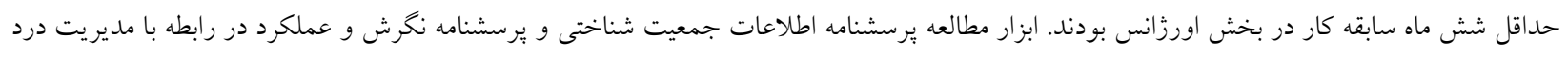

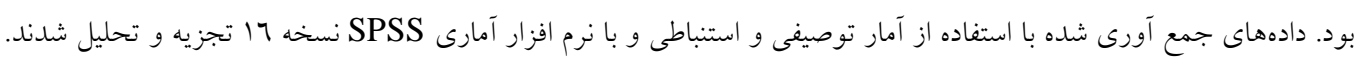

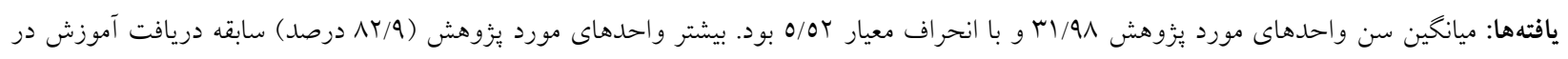

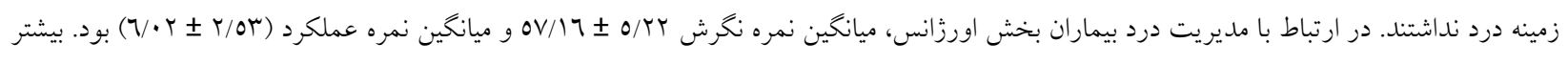

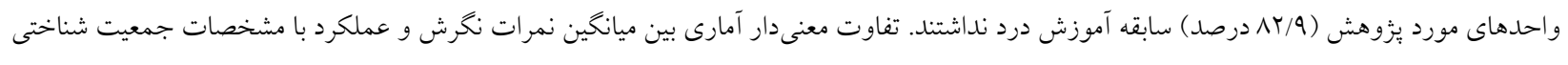

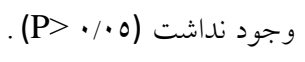

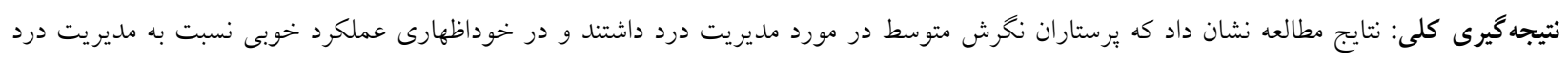

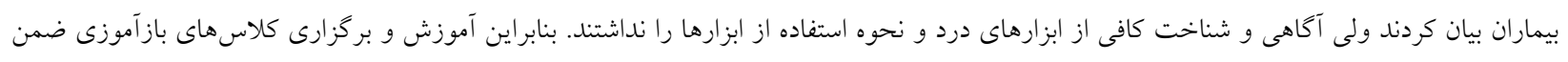

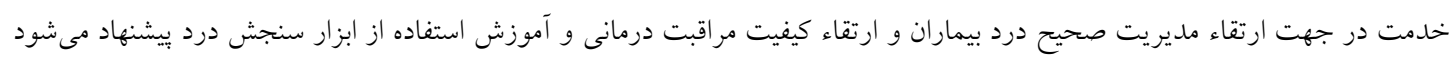

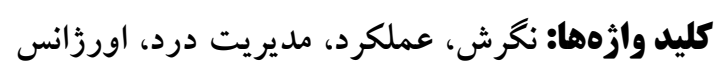

$$
\text { تعارض منافع: ندارد }
$$

تاريخ دريافت: · $9 \Lambda / N / T$

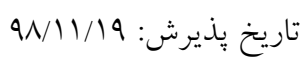

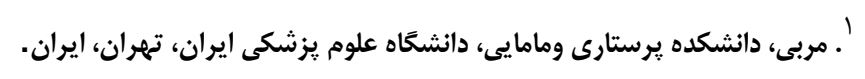

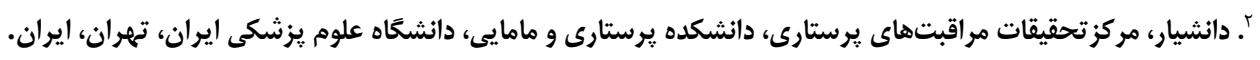

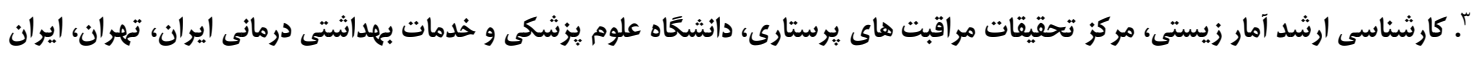

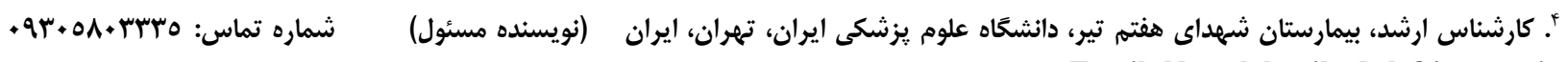


يرستارى و يكى مؤلفه مهم مديريت مؤثر درد بيمار مىباشد (9).

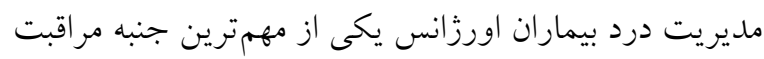
هاى يرستارى و يك بخش اساسى از نقش مراقبى برستاران

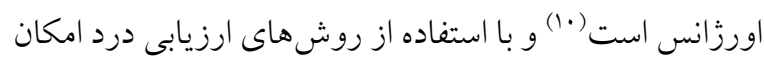
يذير است. با وجود اين كه درد رايجترين علامت در بخش

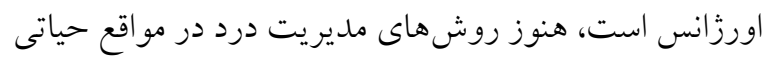

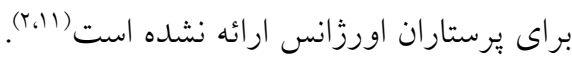

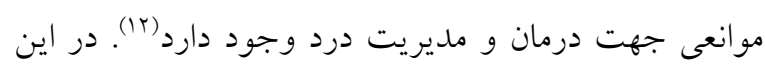
بين مهم است كه موانع تسكين مؤثر درد مشخص و با تدابير مناسب رفع شود(0). موانع و ابهامات سنجش و كنترل درد شامل كمبود وقت و امكانات با بيشترين تأثير، كمبود كاركنان،

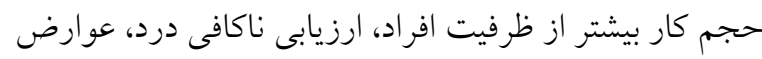

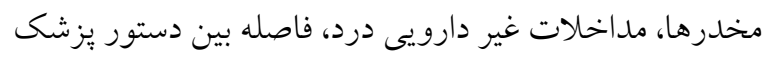
و تجويز دارو با توجه به حجم بالاى كار در بخش اورزانس،

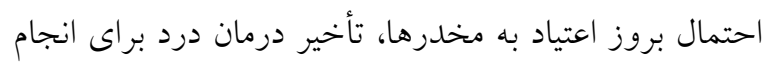
تستهاى تشخيصى، ترس از بروز ديرسيون تنفسى لترنى (Respiratory depression) دانش ناكافى، نخرش منفى و عملكرد ضعيف و عدم مهارت

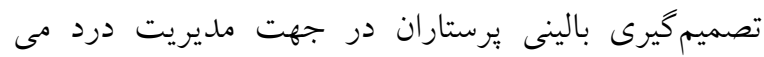

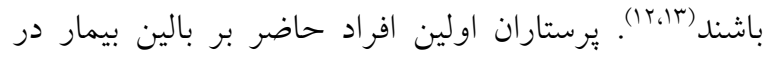
هنگام درد بوده و بيشترين مدت زمان حضور را در كنار بيمار

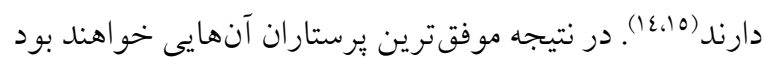
كه شايستكى و تو انايى بررسى درد داشته باشند. لازم است كه يرستاران به مهارتهاى ارتقاء دهنده سطح كيفى مراقبت ها دست يابند و آنها را در عمل به كار كيرند. در اين ميان

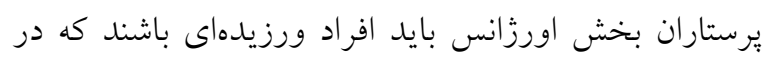

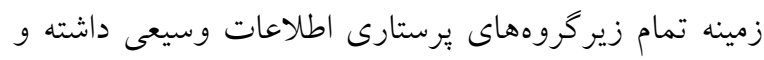
علاوه بر داشتن دانش و مهارت، قادر به قضاوت در موقعيت هاى خطير بالينى، تصميم كيرى جهت حفظ حيات، حل مشكلات ييجيده و تفكر در مواقع بحرانى باشند (17، 1).

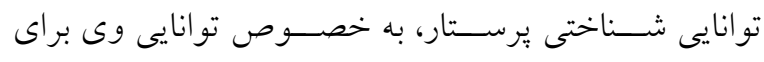

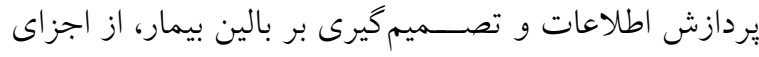

\section{مقدمه}

انجمن بين المللى مطالعه درد (IASPternational : Association for the Study of Pain حسى و احساس ناخوشايند مرتبط با آسيب واقعى يا بالقوه بافتى تعريف مىكند (1). يكى از شايعترين دلايل مراجعه بيماران به بخش اورزانس درد است. بيشتر بيماران حين

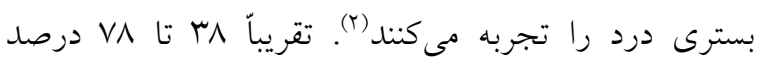
بيماران مراجعه كننده به اين بخش از درد شديد تا متوسط شكايت دارند (َّ). عدم تسكين درد بيماران از مهمترين موضوعات رايج بخش اورزانس است(ع). موفقيت نبودن در

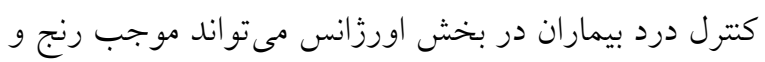

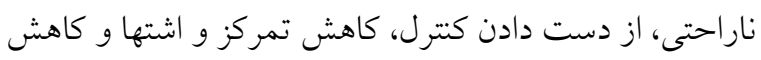
خواب آنان شود (0). مشكلات ديخرى هميجون افزايش طول درمان، عوارض بيمارى و عوارض درمان به طور معنىدارى در افراد با درد تسكين نيافته بالاتر است (7). يكى از دلايل شروع درد شديد در بيماران مىتواند اندازه

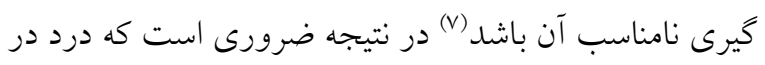
مرحله ابتدايى شناسايى شده و تسكين يابد (0). ارزيابى و سنجش كامل درد بيمار، كليد تأثير كذار در مديريت درد است.

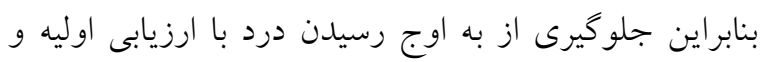

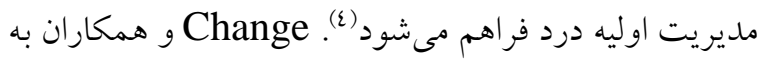
اين نتيجه رسيدند كه يرستاران و يزشكان در ارزيابى و

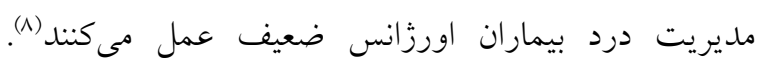

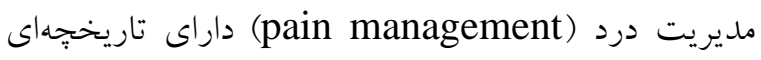
كمتر از دو دهه مىباشد. اخيراً شاخه مديريت درد با راهنماى

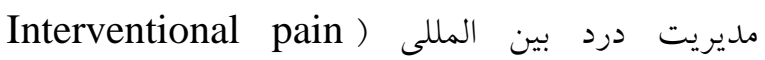
(IPMPs :management procedures كرده است. در بسيارى شهرهاى بزرى آمريكا كلينيكهاى

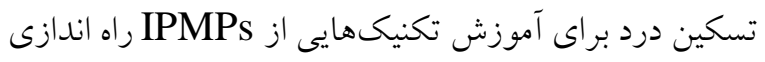

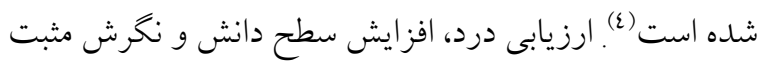
و عملكرد مناسب يرستارى پيايهاى براى انجام مداخلات 
به طور جِشمخيرى منجر به ارزيابى غلط درد شود. بنابراين داشتن نخرش مثبت و عملكرد مناسب در ارزيابى و مديريت

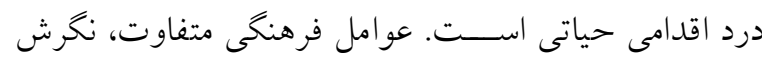
هاى مختلفى در جهت مو افقت يا مخالفت با يكى موضسـوع ايجاد مى كند، و از آن جا كه عوامل مختلف نيز در تثبيت يا

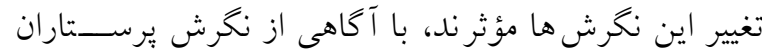

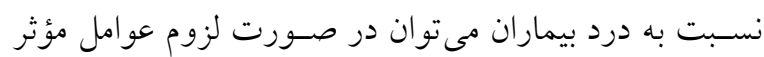
در تغيير يا تثبيت نحرش منفى، به تغيير آن در جهت مطلوب

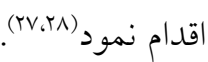
مطالعه مدانلو و همكاران نشــان داد كه حداقل نمره شـــت درد ثبت شده تو سط بيماران 0 بود، در حالى كه •9 در صد بيماران شدت درد خود را بيشترين ميزان اعلام كرده بودند.

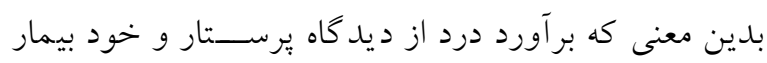

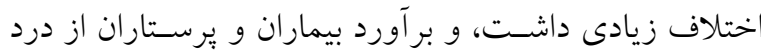

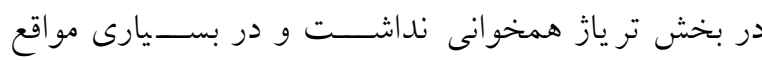

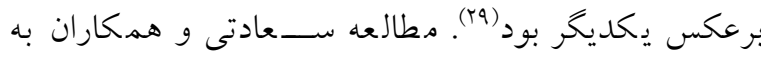

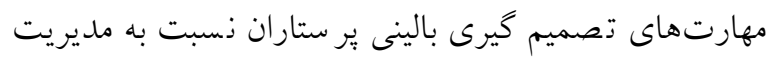

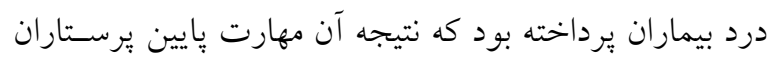
در زمينه مدير يت درد بي مار بود و همجنين دانش كم و نخرش متوسط نسبت به مديريت درد داشتند (rr). مرور منتقدانه بر مطالعات مختلف ذ شان مىدهد كه برر سى نخرش و عملكرد يرستاران نسبت به مديريت درد بيماران در بخش هاى ديخر همجيون بخش مراقبتهاى ويزه انجام شــه است ولى در بخش اورزانس مورد بررسى قرار نخرفته است. در مطـالعـات انجــام شــــــهـ تمركز بر روشهــاى غير فارماكولوزيك و محيطى در تســـين درد، تأثير آموزش در بهبود مهارتهاى يرسـتاران در زمينه شـناخت، بررسـى و كنترل درد، ارتباط نحوه نخرش نســبت به تســــين درد با دريافت مسكن و شدت درد در بيماران مبتلا به سرطان بوده ا ست ولى نخرش و عملكرد ير ستاران در رابطه با مديريرت درد بيماران را مورد بررسى قرار ندادهاند. و يزّوهشخر مطالعه

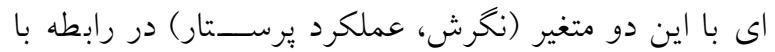

كليدى عملكرد يِرســتار اورزانس مىباشـــــ(IV). آنان دائماً نيازمند تصـميم گيرى در مورد كنترل درد بيماران هسـتند و كنترل مؤثر، نيازمند فرآيند تصميم گيرى صحيح است كه از طريق آكاهى كافى و نخرش مثبت در ارتباط با درد و درمان آن ميسر مىباشد (1). مديريت مناسب درد بستكى به بررسى سيستماتيك و صحيح درد جهت راهنمايى در تصميم گيرى براى تيتر كردن ضــد دردها و تجويز داروهاى "در صـورت نياز" دارد(19). با تو جه به نقش عمده برســـاران در ارائه

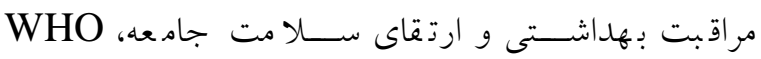
بر انتقـال قــدرت (World Health Organization) تصـميم گيرى و مداخله به آنها، به عنوان خطوط مقدم ارائه

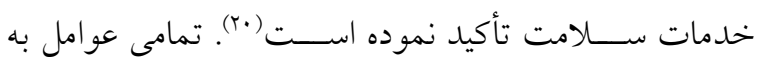
همراه ارتقاء مهارتهاى بالينى برســتار جهت مديريت درد بي مار مىتواذند تســكين درد را به طور مؤثر تســــيل

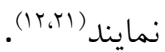

كزارش بيمار قابل اعتمادترين و دقيقترين شاهد براى وجود درد و شدت آن است و به عنوان استاندارى طلايى از آن ياد مى شود (rr). بـ إز ايس كه درد تو سط بيمار كزارش مى شود يز شك مربوطه تصميم مى گيرد كه جهه مسكنى تجويز نمايد و بر ستار با در نظر كرفتن شرايط و سودمند بودن تصميم

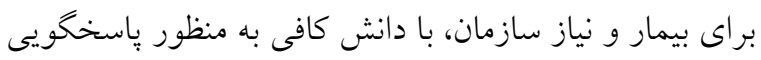

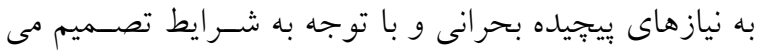

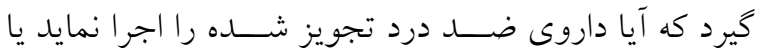

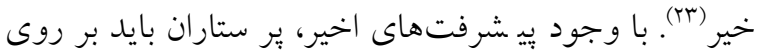
مشــكلات بيمار با هدف مديريت مؤثر درد تمركز كنند (عَ).

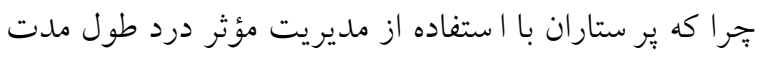

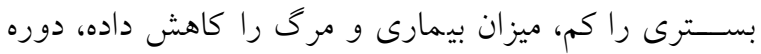
بـ سترى شدن را كم كرده، و سبب افزايش ر ضايت بيماران

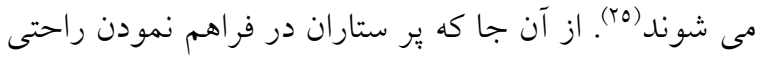

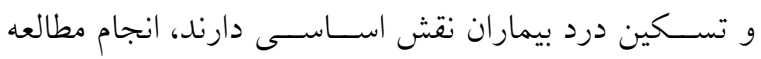

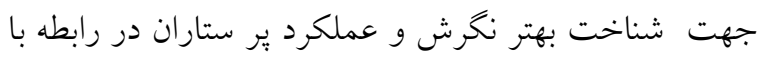

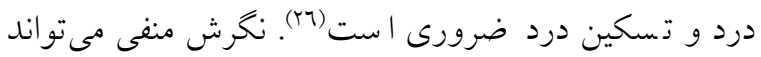


عملكرد برسـتاران در رابطه با مدير يت درد جمع آورى

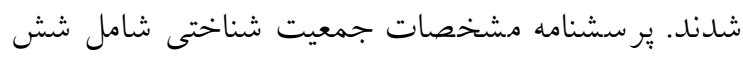
سئوال در مورد سن، جذسيت، سابقه كار، سابقه كار در

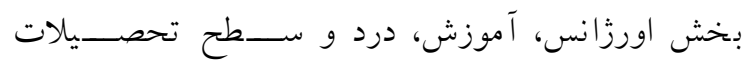

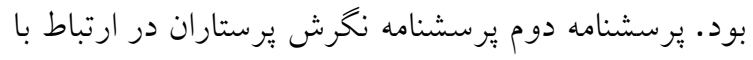

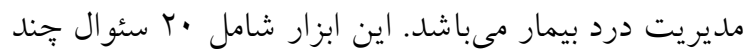

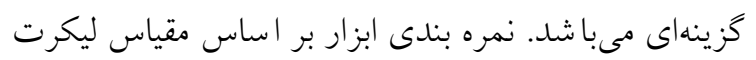

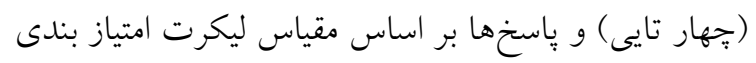

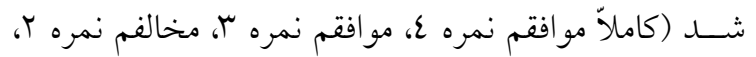

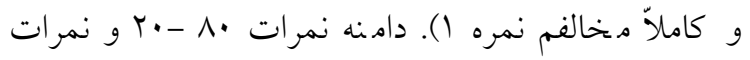

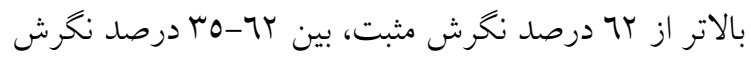
متو سط، و زير Oب در صد نشان دهنده نخرش منفى نسبت ديت دين

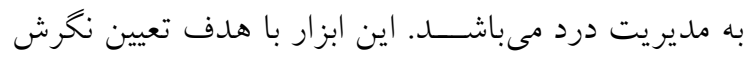

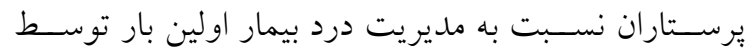

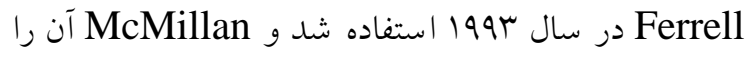

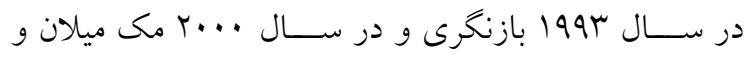

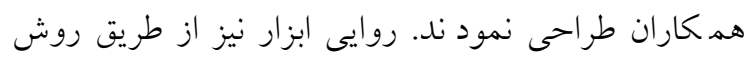

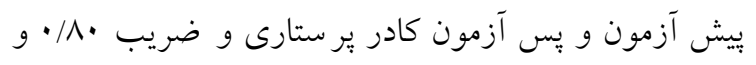
ارزيابى انسـجام داخلى ضـريب آلفاى كرونباخ •V/ • تأييد

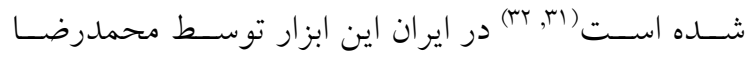

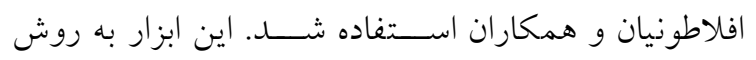
ترجمه به فار سى بركردان تو سط تيم يزوهش در دانشكده

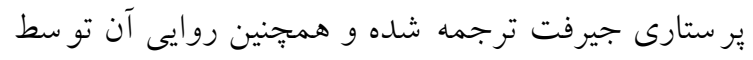

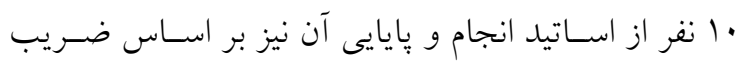

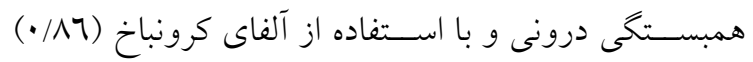
كزارش گرديده اسـت. ثبات درونى در اين مطالعه با آلفاى

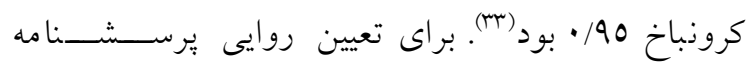

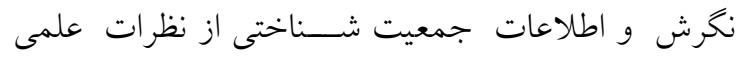

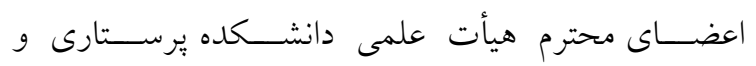

مديريرت درد بيماران در بخش اورزانس در ايران نيافت لذا

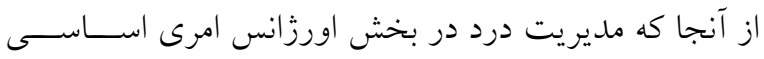

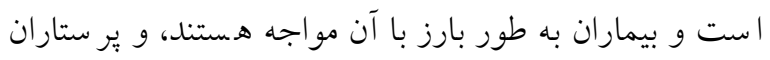

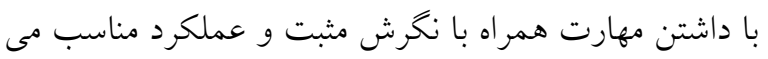

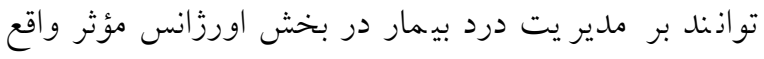

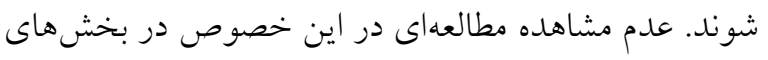

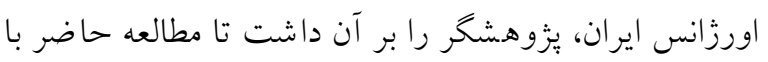
هدف تعيين نخرش و عملكرد ير ستاران در رابطه با مديريت

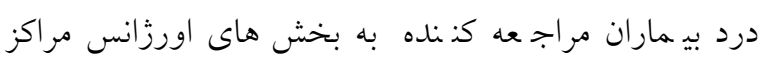

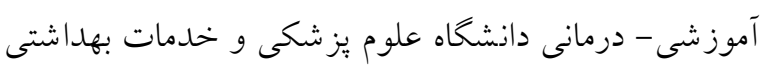

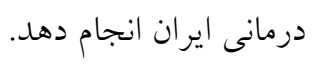

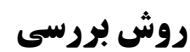

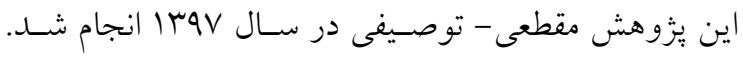
جامعه يُزوهش را تمامى برستاران شاغل در بخش اورزانس

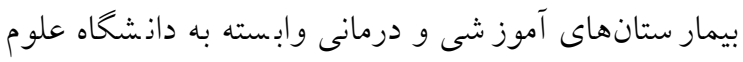

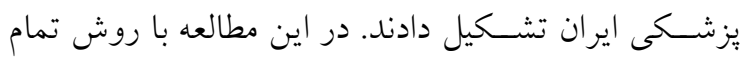

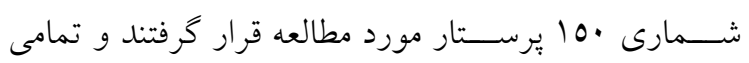

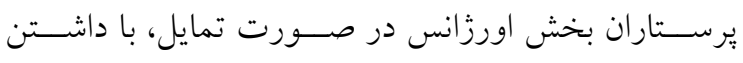

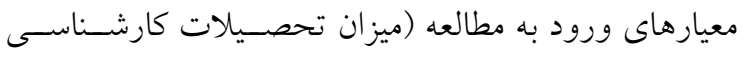

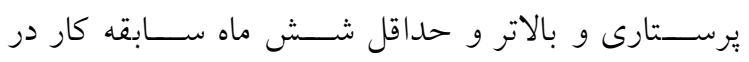

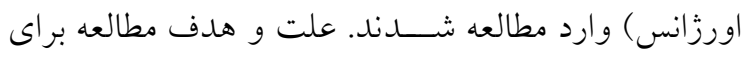

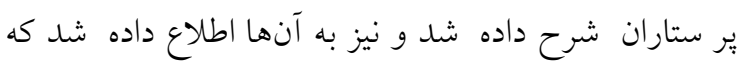
حضور شان در اين مطالعه كاملاً اختيارى بوده و هيج كونه دئه

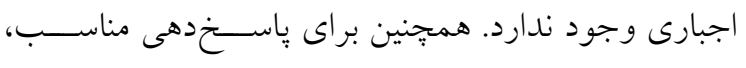

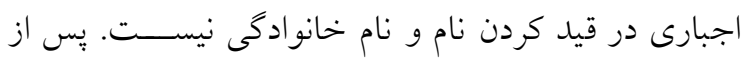
تحويل يرســــنامهها دو نفر از شــركت كنندكان به دليل ر ضايت ندا شتن براى مـشاركت، از مطالعه خارج ش شدند. بر سشنامهها ابتداى نوبت كارى به ير ستاران داده شد تا در

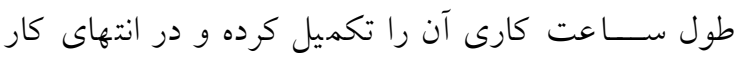
تحويل دهند. دادهها با اسـتفاده از يرسـشــنامه اطلاعات

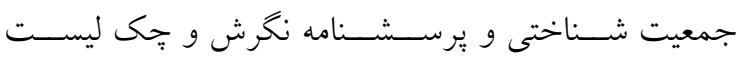


مـــــ.IUMS.FMD.REC.1396.9411706008)

كرفته شـــد. براى آناليز دادهها از آمار توصــيفى (ميانخين،

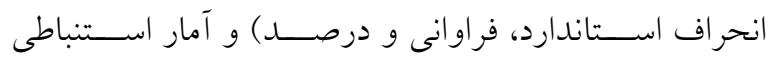

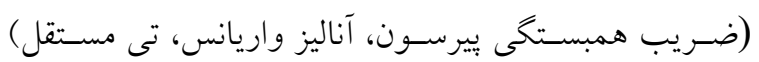

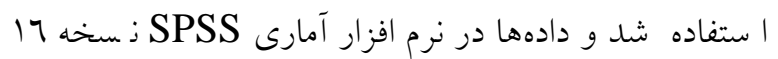
تجزيه و تحليل گرديد.

\section{يافتهها}

شركت كنندگان در اين مطالعه شامل •10 يُرستار شاغل در بخش اورزانس بودند. يافتهاى حاصل از مطالعه نشان داد

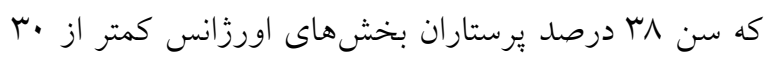

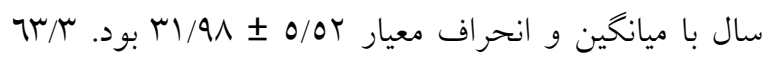

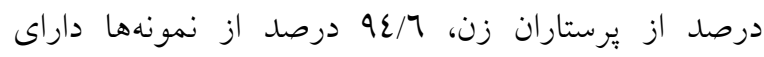
تحصيلات كارشناسى، وس درصد نمونهها سابقه كار بين 7 تا

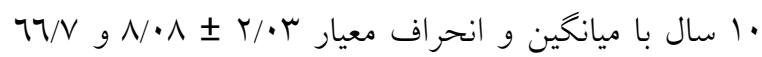

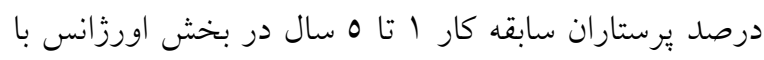

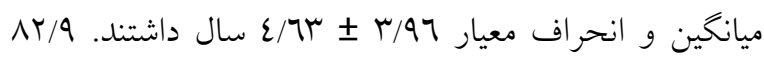
درصد از ياسخ دهندكان دورههاى آموزش درد را نحخدرانداه

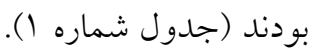

مامايى ايران نيز استفاده شد. نمره بِايايى اين ابزار يا همان

$$
\text { آلفاى كرونباخ 90/ • به دست آمد. }
$$

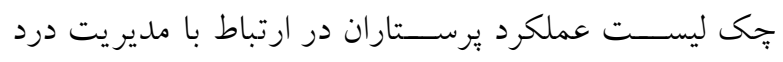

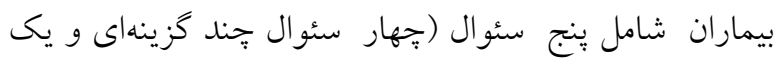
سئوال تشريحى) مىباشد. ير سشنامه تو سط يرستار ان شركت كننده در مطالعه (به صـورت خوداظهارى) تكميل شـــ. نمره بندى ابزار بر اساس بله با نمره ؟، تا حدودى با نمره ا و خير

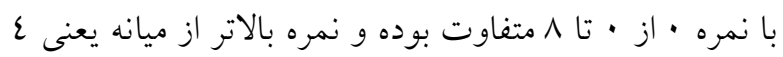

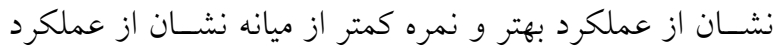

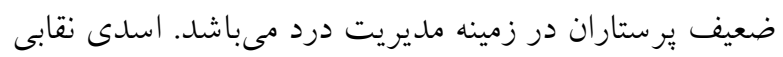

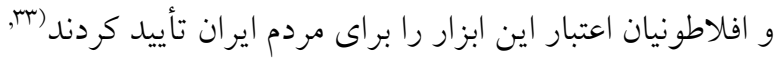

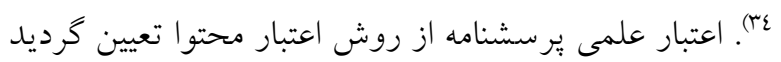
و نمره بايايى اين ابزار با آلفاى كرونباخ ب0 190 • بود.

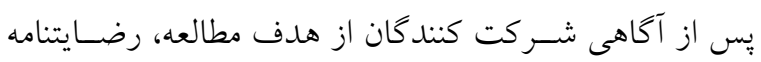

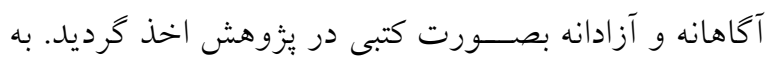
يرسـتاران اطمينان داده شـــ كه حضـورشــان در اين مطالعه

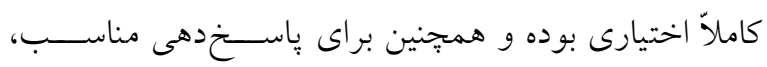

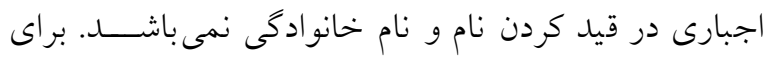
انجام اين مطالعه از كميته اخلاق دانشگاه علوم بز شككى ايران

\begin{tabular}{|c|c|c|c|c|c|c|c|c|}
\hline \multirow[t]{2}{*}{ آزمون } & \multicolumn{2}{|c|}{ عملكرد } & \multirow[t]{2}{*}{ آزمون } & \multicolumn{2}{|c|}{ 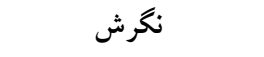 } & \multirow{2}{*}{ متغيرهاى جميعت (درصناختى } & & \multirow{2}{*}{ شتغير جمعيت } \\
\hline & انحر افمعيار & ميانخين & & انحر افـعيار & ميانخين & & & \\
\hline$F=r / T \Lambda \Lambda$ & 1/No & $0 / 21$ & $F=1 / 70$. & $\varepsilon / \cdot \wedge$ & $O V / \varepsilon)$ & $\varepsilon\rceil(\Upsilon \wedge / \cdot)$ & زير •rسال & \multirow{3}{*}{ سن } \\
\hline \multirow[t]{2}{*}{$\mathrm{P}$-value $=\cdot / \cdot \mathrm{Vr}$} & $1 / 7 \varepsilon$ & $7 \cdot 0$ & $\mathrm{P}$-value $=\cdot / 19 \mathrm{~V}$ & $O / V$ & ov & ro $(Y N / q)$ & $r \cdot-r \varepsilon$ & \\
\hline & $1 / 17$ & $T / Y 7$ & & $\varepsilon / 1$ & ON/N & $\varepsilon \cdot(\mu \Gamma / 1)$ & هץ و بالاتر & \\
\hline \multirow{3}{*}{$\begin{array}{c}\mathrm{t}=\cdot / \wedge \backslash \mid \\
\mathrm{df}=\mid \varepsilon \wedge \\
\mathrm{P} \text {-value }=\cdot / \varepsilon \backslash \wedge\end{array}$} & $1 / 7 V$ & $7 / 1$. & $\mathrm{t}=1 / T \varepsilon r$ & $\varepsilon / N \mu$ & $O V / O \varepsilon$ & $90(7 \pi / \Gamma)$ & زن ان & \multirow[t]{3}{*}{ جنسيت } \\
\hline & $1 / 71$ & $0 / 17$ & $\mathrm{df}=\mid \varepsilon \wedge$ & $0 / \varepsilon V$ & $07 / 29$ & 00 (rT/ov) & 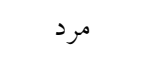 & \\
\hline & & & $\mathrm{P}$ - value $=\cdot / \pi / 7$ & & & & & \\
\hline \multirow{5}{*}{$\begin{array}{c}\mathrm{F}=\cdot / \cdot \mathrm{\wedge} \\
\mathrm{P} \text {-value }=\cdot / \wedge 17\end{array}$} & $1 / \wedge \varepsilon$ & o/or & & $\varepsilon / 00$ & OV/ar & $\varepsilon r\left(r_{0} / \cdot\right)$ & $1-0$ & \multirow{4}{*}{ سابقه كار } \\
\hline & $1 / 21$ & $T / Y_{1}$ & $\mathrm{~F}=\cdot / r \cdot r$ & $0 / 7 \mathrm{~V}$ & $O V / T$ & $\varepsilon \wedge(r q / \cdot)$ & $7-1$ & \\
\hline & $r / \bullet \wedge$ & $0 / 19$ & $\mathrm{P}$-value $=\cdot / 9 \mathrm{Mr}$ & $\varepsilon / 0 r$ & $0 \Lambda / \cdot \Lambda$ & $Y I(I V / I)$ & $11-10$ & \\
\hline & $1 / 79$ & o/VA & & $7 / 27$ & OV/Vr & $V(0 / V)$ & $>17$ & \\
\hline & $1 / 0 \mathrm{~V}$ & $0 / 99$ & & $0 / 10$ & $07 / 71$ & $1 \cdots(77 / v)$ & $1-0$ & \\
\hline
\end{tabular}

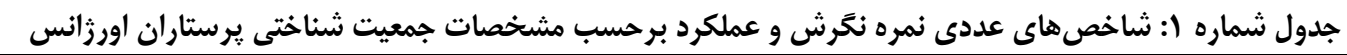




\begin{tabular}{|c|c|c|c|c|c|c|c|c|}
\hline$F=\cdot / \Lambda r V$ & $1 / 9$ & $0 / 9 r$ & $F=r / \varepsilon r \mu$ & $\varepsilon / \Lambda \Lambda$ & $01 / 09$ & $\sum Y(Y \wedge / \cdot)$ & $7-1 T$ & سابقه كار در \\
\hline$P$-value $=\cdot / \varepsilon r q$ & $1 / 20$ & T/Vo & $\mathrm{P}$-value $=\cdot / \cdot 91$ & $T / T$. & $07 / 0$. & $\wedge(0 / \Gamma)$ & $>1 r$ & بخش \\
\hline$t=\cdot / v r \varepsilon$ & $1 / \mathrm{V}$ & $T / T_{0}$ & $t=\cdot / 0 r \mu$ & $7 / \cdot 0$ & $0 V / 70$ & ro $(I \mathrm{~V} / \mathrm{I})$ & دارم & \\
\hline $\mathrm{df}=\iota\{\wedge$ & $1 / 79$ & $0 / 9 \mathrm{~V}$ & $\mathrm{df}=\backslash\{\wedge$ & $\varepsilon / \wedge \vee$ & $0 V / \cdot 7$ & $|r|(\Lambda Y / q)$ & ن ندارم & آموزش درد \\
\hline $\mathrm{P}$-value $=\cdot / \varepsilon 7 \varepsilon$ & & & P-value $=\cdot / \tau \cdot r$ & & & & & \\
\hline$Z=1 / \wedge \varepsilon 0$ & $1 / 01$ & $7 / 1$ & $\mathrm{Z}=\cdot / 700$ & $0 / 14$ & OV/TM & $\| \mu \wedge(9 \varepsilon / 7)$ & كارشناسى & سطح \\
\hline $\mathrm{P}$-value $=\cdot 1 \cdot 70$ & T/OT & $\varepsilon / 0$ & P-value $=\cdot / 01 \mathrm{r}$ & $r / \varepsilon 0$ & $00 / 91$ & $\wedge(0 / \varepsilon)$ & كارشناسى & تحصيلات \\
\hline
\end{tabular}

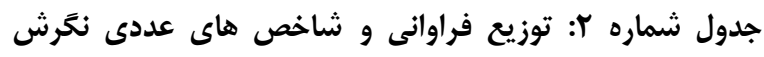

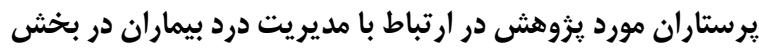

اورزانس

\begin{tabular}{|c|c|c|}
\hline درصد & فراوانى & ن نكرش \\
\hline$\Lambda T N$ & $T r \varepsilon$ & متوسط (rاY-TO) \\
\hline$I V \mu$ & r & مثبت (بالاى كآ) \\
\hline $1 \cdots$ & 10. & جمع كل \\
\hline \multicolumn{2}{|c|}{$0 V / 17 \pm 0 / . r Y$} & انحراف معيار 土 ميانكين \\
\hline \multicolumn{2}{|c|}{$r u-V r$} & بيشينه-كمينه \\
\hline
\end{tabular}

مطابق جدول شماره ب فراوانى و در صد يا سخ به سئوالات

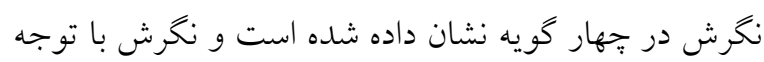
به ياسـَخ به سـئوالات مورد بررسسى قرار كرفت. بيشـترين

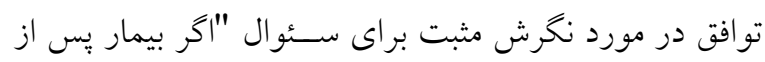

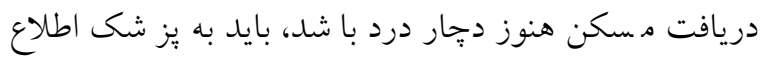

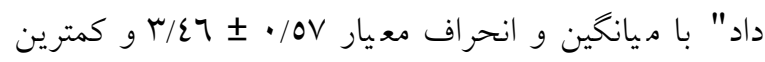

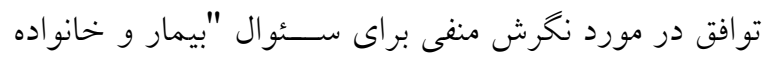

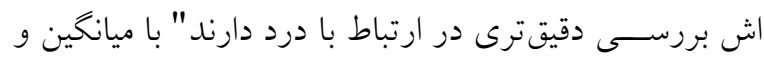

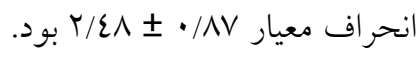

مطابق با جدول شماره ا، نخرش و عملكرد با هيج يك از

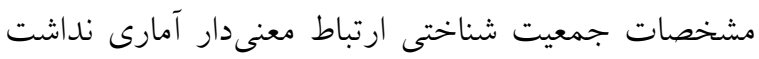
(P> • / م). در ضمن ضريب همبستكى بيرسون نشان دهنده

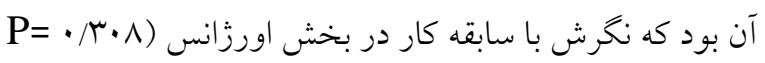
,

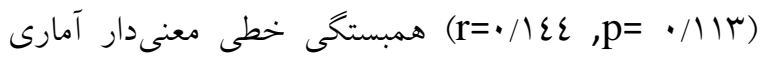
نداشتند. عملكرد نيز با سابقه كار در بخش اورزانس

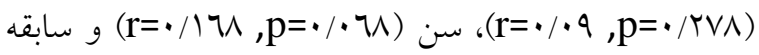

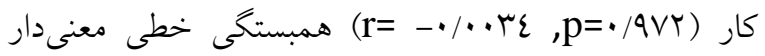

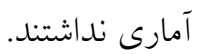
همان طور كه جدول شـماره r نشــان مىدهد هيج كدام از

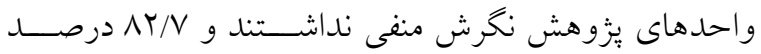

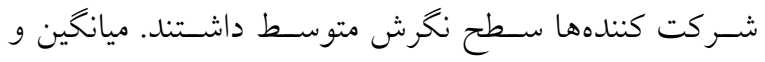

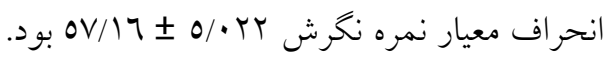


جدول شماره ץ : توزيع فراوانى و شاخص عددى سوالات نكَرش برستاران مورد يزوهش در ارتباط با مديريت درد بيماران در بخش اورزانس مقياس ليكرت

士

\begin{tabular}{|c|c|c|c|c|c|}
\hline & فراوانى (درصد) & فراوانى (درصد) & فراوانى (درصد) & فراوانى (درصد) & سئوالات \\
\hline$r / \Lambda \Gamma \pm \cdot / \Lambda T$ & $(\Lambda / 1) \mid r$ & $(r \mu) \Gamma \varepsilon$ & $\left(\sum 7 / 7\right) 79$ & $(r T / r) \mu r$ & بيان درد توسط بيمار معتبرترين كزارش است. \\
\hline$r / 乏 \wedge \pm \cdot / \wedge \vee$ & $(\mid \varepsilon / r) \Gamma$ & $($ ro/1) or & $(r q / Y) \circ \Lambda$ & $(11 / 0) \mathrm{IV}$ & بيمار و خانو ادهاش بررسى دقيق ترى در ارتباط با درد دارند. \\
\hline$r / \mu 1 \pm \cdot / 70$ & $(1 / \varepsilon) r$ & $(T / 1) 9$ & $(O Y / \varepsilon) V V$ & $(\varepsilon \cdot / 1) 09$ & بررسى مداوم درد و اثربخشى دارويى در مديريت مؤثر درد الزاميست. \\
\hline$r / r \cdot \pm \cdot N \cdot q$ & $(1 / \varepsilon) r$ & $(1 Y / \Lambda) 19$ & $(0 \cdot) \vee \varepsilon$ & $($ ro/A ) or & عدم بيان درد الزاماً به معناى عدم وجود درد نيست \\
\hline$r / 0 \varepsilon \pm \cdot / V q$ & $(9 / 0) \mid \varepsilon$ & $($ MT/N) or & $(\varepsilon \varepsilon / T) 70$ & $(9 / 0) \backslash \varepsilon$ & بيمار بايد در وضعيت بدون درد نكه داشته شود. \\
\hline$r / \Lambda \pm \cdot / V \varepsilon$ & $(19 / 7) \varepsilon$ & $(r \tau / \varepsilon) r q$ & $(01 / \varepsilon) \vee 7$ & $(19 / 7) r 9$ & مؤثر كترل ثنابت بى حسدى بايد در خون موجود بوده تا درد به صسورت \\
\hline$r / V\urcorner \pm \cdot / N r$ & $(\mathfrak{\varepsilon} / 1)\urcorner$ & $(r q / V) \varepsilon r$ & $(0 Y / \varepsilon) V\urcorner$ & $(I r / \Lambda) r \cdot$ & بيمار بايد قبل از تجويز دوز مسكن درد را تجربه كند. \\
\hline T/VO $\pm \cdot / V T$ & $(7 / 1) 9$ & $(r \tau / \varepsilon) r q$ & $(0 \Sigma / 1) \wedge$. & $(\mid r / 0) r$. & 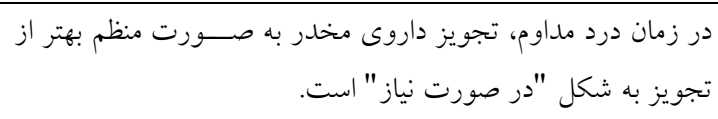 \\
\hline r/AT $\pm \cdot /$ VO & $(\xi / \Lambda) \vee$ & $(Y I / 9) r Y$ & $(0 T / Y) \wedge r$ & $(I V / I)$ ro & بيمار انى كه بهصورتمنظممخدردريافتمى كنند، بيشتردر خطر اعتياد هستند. \\
\hline$r / 9 \pm \cdot / N T$ & $(r \cdot / \Lambda) r$. & $(r q / q) \varepsilon r$ & $(\Sigma \Lambda / \tau) V$. & $(r \cdot / \Lambda) r$. & داروهاى مخدر هستند علايم فيزيكى و نياز به بى حســى از علايم اعتياد بيمار به \\
\hline$r / \neg \Lambda \pm \cdot / V \Lambda$ & $(\mathrm{T} / \mathrm{N}) 1$. & $(r \mid / 0)\{\rceil$ & $\left(\sum \Lambda / 7\right) V I$ & (1r) 19 & بيماران كه مخدر "در صورت نياز" دريافت مى كند بيشتر در خطر \\
\hline$T / V I \pm \cdot / V \varepsilon$ & $(\Sigma / 1) 7$ & $(\pi / \mu) \varepsilon q$ & $(\varepsilon q / V) V r$ & $(1 Y / 9) 19$ & 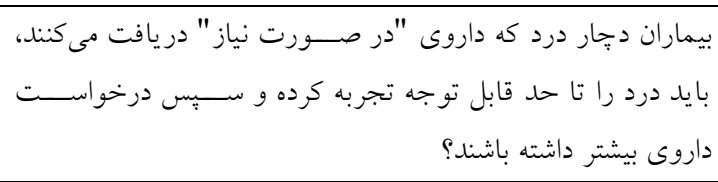 \\
\hline 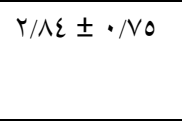 & $(T / V) \varepsilon$ & $(r q / V) \varepsilon \varepsilon$ & $(\Sigma N / T) V r$ & $(1 \Lambda / 9) Y \Lambda$ & 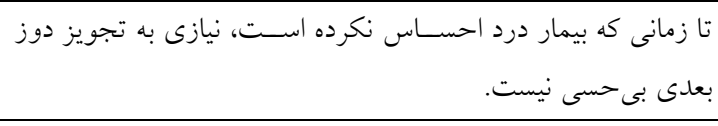 \\
\hline$r / 10 \pm \cdot / 77$ & $(1 / \varepsilon) r$ & $(Y T / 0) r q$ & $(O V / \Lambda) \wedge 0$ & $(\mid \varepsilon / \Gamma) \Gamma$ & توجه به وجود يار داراى درد مزمن بايد دارو را با فو واصود نار احتى دريافت كنند. \\
\hline$r / O \Lambda \pm \cdot / V \varepsilon$ & $(9 / 0) \mid \varepsilon$ & $(r q / r) \varepsilon r$ & $(00 / 1) \wedge 1$ & $(7 / 1) 9$ & بيماران را مىتوان در وضعيت بدون درد نخحه داشت. \\
\hline T/NY $\pm \cdot / V A$ & $(\varepsilon / \Lambda) \vee$ & $(T V / \varepsilon) \varepsilon$. & $(\Sigma q / r) V Y$ & $(1 N / 0) T V$ & 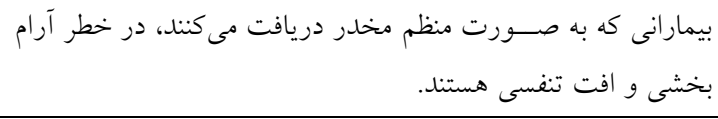 \\
\hline$r / 9 r \pm \cdot / v \cdot q$ & $(\Sigma / 1) 7$ & $(17 / \mu) T \varepsilon$ & $(71 / 9) 91$ & $(I V / V) Y \nearrow$ & دوز كمتر مسكن رار (يا خانواده وى) كاهش درى تجود و افوريا را كزارش كند، بايد \\
\hline$r / \Lambda 1 \pm \cdot / N r$ & $(\Gamma / \varepsilon) 0$ & $(Y V / V) \varepsilon l$ & $(0 r / \varepsilon) \vee q$ & r & برد حيمارانى كه درد شديد مزمن دارند دارند به دوز بالاترى مسكن نسبت به \\
\hline$r / \varepsilon 7 \pm \cdot / 0 V$ & $(\cdot) \cdot$ & $(\Sigma / 1) 7$ & $(\varepsilon 0 / 9) \mathrm{Th}$ & $(0). V \varepsilon$ & اكربيماريسازدريافتمسكن هنوز دجار درد باشد، بايد به يزشك اطلاع داد. \\
\hline$r / 91 \pm \cdot / 99$ & 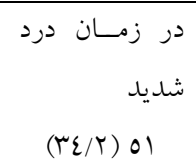 & 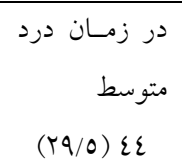 & در زم مان وجود & 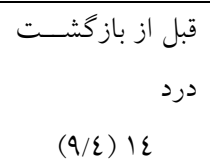 & 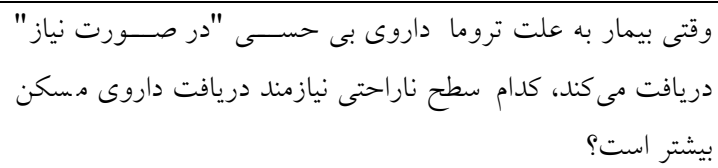 \\
\hline
\end{tabular}


در ير سـ شنامه خودگزارش دهى عملكرد •7 نفر بيان كردند

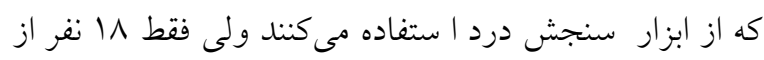

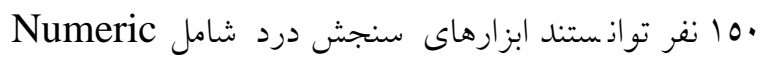
،Visual Analog Scale (Pain Ratings Scale McGill Pain Questionnaire ا ستفاده از تصاوير جهره و رفتار را نام ببرند و ذشان دهنده

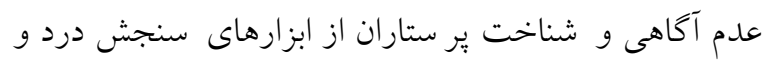

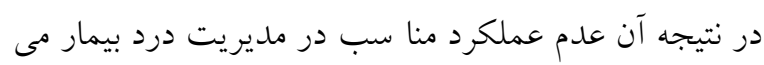
باشد. (جدول شماره 0)

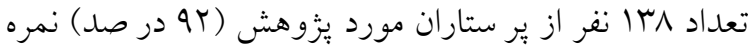
بالاتر از ع داشتند كه حاكى از عملكرد مطلوب بر ستاران در

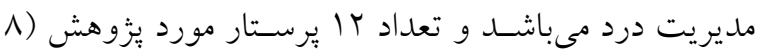
درصـــــ نمره كمتر از ع داشــتهن كه حاكى از عملكرد

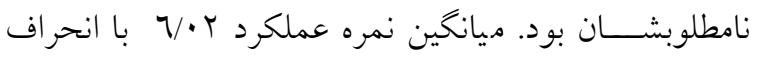
معيار r/Or بود (جدول شماره ع).

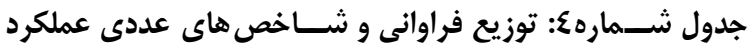

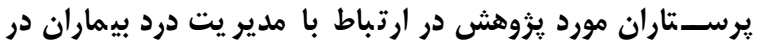
بخش اورزانس

\begin{tabular}{|c|c|c|}
\hline درصد & فراوانى & عملكرد \\
\hline 94 & $\mid r \Lambda$ & مطلوب (نمرات كمتر از ع) \\
\hline$\wedge$ & ir & نامطلوب (نمرات ع و بيشتر) \\
\hline \multirow[t]{3}{*}{$1 .}$. & 10. & جمع كل \\
\hline & $T / r \pm r / O r$ & انحراف معيار 土 ميانكين \\
\hline & $\cdot-\Lambda$ & بيشينه - كمينه \\
\hline
\end{tabular}

جدول شماره 0: توزيع فراوانى عملكرد ير ستاران مورد يزوهش در ارتباط با مديريت درد بيماران در بخش اورزانس خير تاحدودى

\begin{tabular}{|c|c|c|c|}
\hline بله & 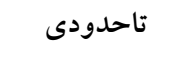 & خير & 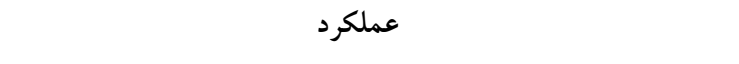 \\
\hline ( $($ ) & (1) & $(\cdot)$ & \\
\hline فراوانى (درصد) & فراوانى (درصد) & فراوانى (درصد) & \\
\hline$(v \cdot / 1) 1 \cdot r$ & $(T O / T)$ rV & $(\varepsilon / \Lambda) \vee$ & وجود و يا عدم وجود درد بيمار را بررسى و ثبت مى كنم. \\
\hline$(70 / 1) 90$ & $($ (YN/I)乏 & $(\mathrm{T} / \mathrm{\Lambda}) 1 \cdot$ & نوع درد را بررسى و ثبت مىكنم \\
\hline ( १) $1 \ldots$ & $(r q / r) \varepsilon r$ & $(Y / V) \varepsilon$ & در صورت وجود درد روشهاى تسكين درد را بررسى و ثبت مى كنم \\
\hline$(\varepsilon / / 1) 7$. & $(r 1 / 0) \varepsilon 7$ & $(T V / \varepsilon) \varepsilon \cdot$ & جهت بررسى مقدار و شدت درد از ابزار استاندارد استفاده مى كنم. \\
\hline
\end{tabular}

كردد كه منجر به ارتقاء دانش و نكرش برستاران شود. طبق بحث و نتيجه كيرى

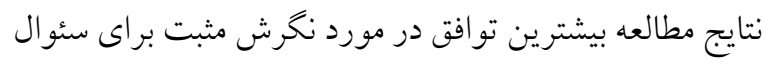
نتايج حاصل از مطالعه حاضر نشان داد كه يرستار بران شاغل در

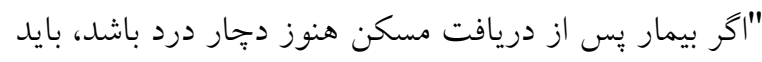
بخش اورزانس نخرش متوسط در مورد مديريت درد بيماران

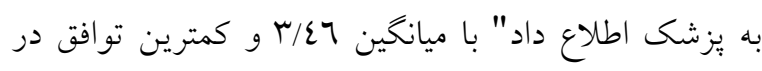

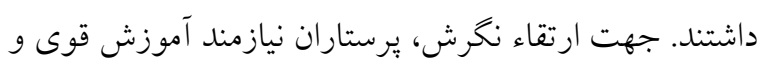

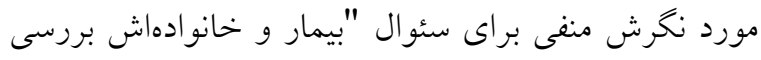

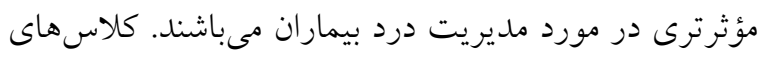

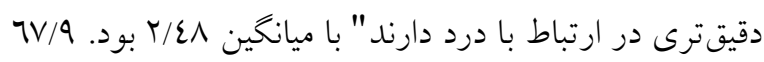

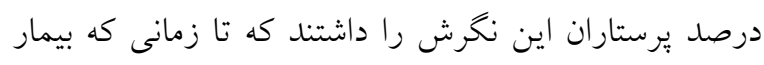

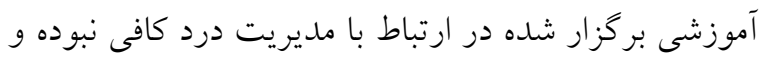

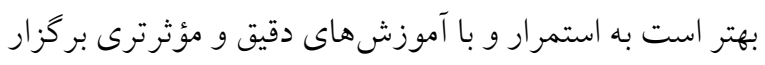


عملكرد از نمره ميانه ابزار بالاتر بوده و نشان دهنده عملكرد خوب برستاران بود. مطالعه Gunningberg در برستاران يك بيمارستان دانشگاهى سوئد نشان داد كه بيماران، به ويزه در بخش عمومى، كيفيت مديريت درد را به ميزان قابل توجهى كمتر ارزيابى كردند. در هر دو بخش، زمينههايى براى بهبود در تمام مقياسهاى ابزار SCQIPP (ارتباط، عمل،

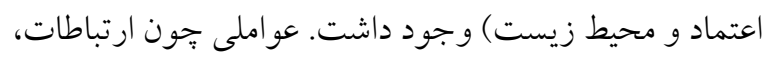
عمل، اعتماد و محيط زيست بر روى درد بيمار تأثير خذار

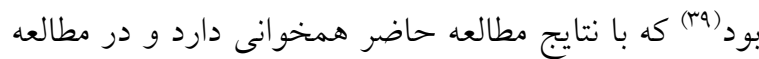
حاضر تنها //اع درصد جهت بررسى مقدار و شدت درد از ابزار استاندارد استفاده مى كنند. مطالعه قربانى و همكاران در برستاران شاغل در بخشهاى

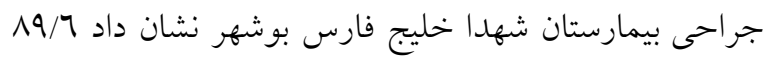
درصد يرستاران از عملكرد بالا و خيلى بالا در ارتباط با بهاب

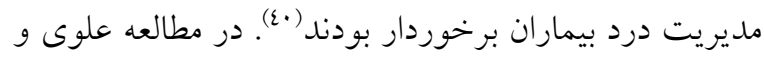

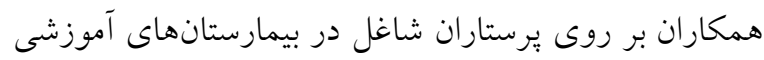

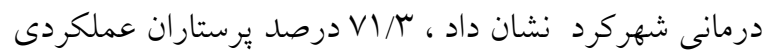

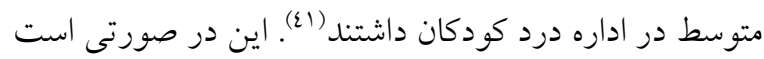
كه در مطالعه Alzghoul و درباره آكاهى و عملكرد يرستاران از اداره غيردارويى درد، عملكرد كاركنان يُرستارى

$$
\text { ضعيف كزارش شده است (كץ). }
$$

تحليل دادهها نشان داد كه بيشتر برستاران بر اساس برسشنامه خوداظهارى وجود و يا وجود نداشتن درد بيمار را بررسى و ثبت مى كنند. اين در صورتى است كه دانش كم و نخرش متوسط در زمينه مديريت درد و شناخت ضعيفى در ارتباط با ابزارهاى سنجش درد داشتند به طورى كه تعداد كمى از يرستاران مورد يزوهش اظهار داشتند كه جهت بررسى مقدار و شدت درد از ابزار استاندارد استفاده مى كنند و نيز تنها تعداد 1/ نفر از •10 نفر برستاران مورد يزوهش توانستند ابزار

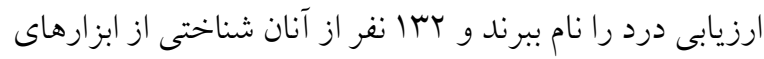

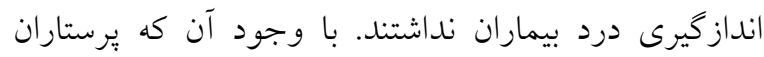

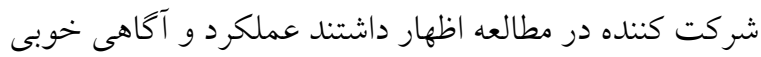

درد احساس نكرده است، نيازى به تجويز دوز بعدى بى حسى

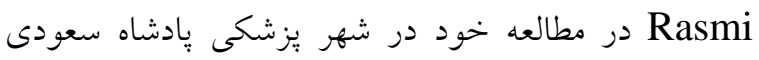
(KSMC) King Saud Medical City يزوهش عُ+r يرستار شاغل در بخشهاى ويزه شهر يزشكى

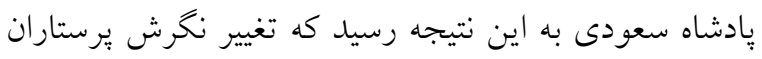

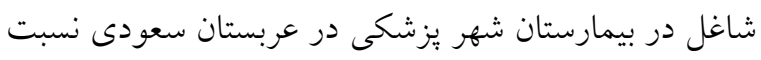

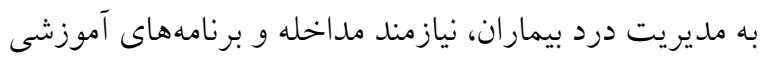

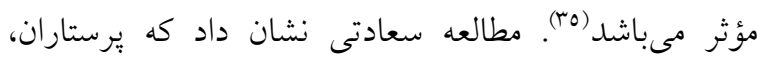
نخرش كم نسبت به شناخت، بررسى و كنترل درد بيماران

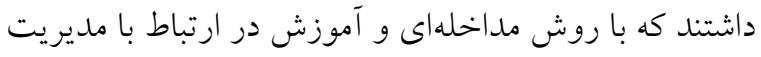

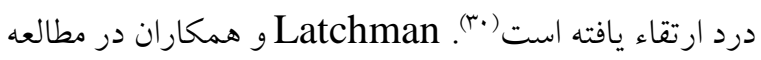
خود بر روى دانشجويان يرستارى در ايالت همبشاير آمريكا

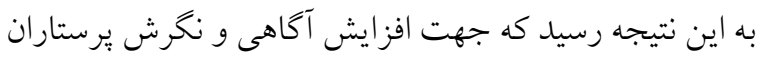
در ارتياط با مديريت درد بيماران، نياز مداوم به برنامه

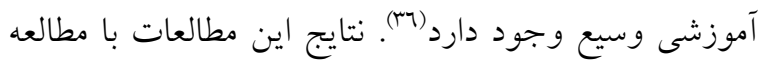
حاضر همخوانى دارد. بر خلاف مطالعه حاضر، مطالعه اسدى نقابى و همكاران در

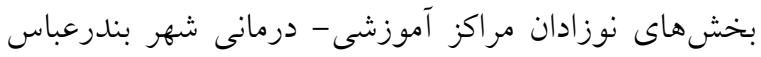

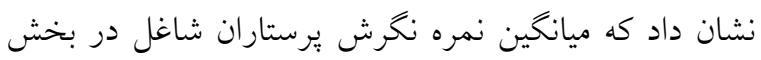
هاى نوزادان ץr/ع از •آ نمره بود و بيشتر برستاران در مورد

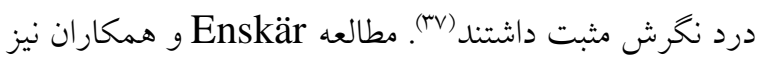
نشان داد كه يرستاران سوئدى نه تنها از دانش بالايى در ارتباط با سنجش درد برخوردارند بلكه نخرش مثبتى نيز به درد دارند

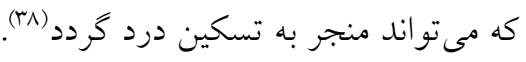

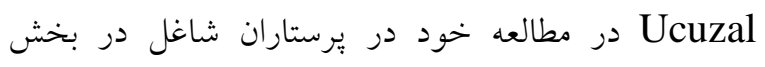
اورزانس نشان داد تنها /هץ درصد يرستاران ميزان درد را ثبت مىكردند. علاوه بر تمام توصيههاى تحقيقات قبلى، يرستاران اورزانس هنوز مهارت تصميمگيرى بالينى كافى نداشتند (ז'). اين در حالى است كه در مطالعه حاضر 10/1 درصد به صورت خودخزارش دهى بيان كردند كه نوع درد را بررسى و ثبت مى كنند. مطالعه نشان داد كه ميانخين نمره 
به بر كردن ير سـشنامهها در همان لحظه نبودند كه براى رفع

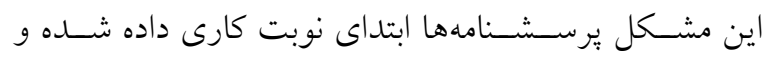

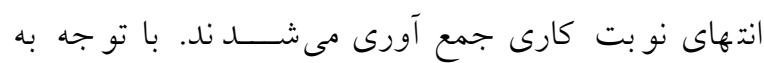

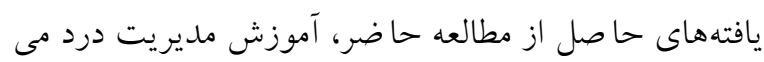
تواند در افزايش نخرش و بهبود عملكرد يرســتاران مؤثر باشد. بنابراين آموزش دورهاى، فراهم كردن امكانات ارزيابى و سنجش درد و ايجاد خط مشى و روشهايى جهت ارزيابى بنى

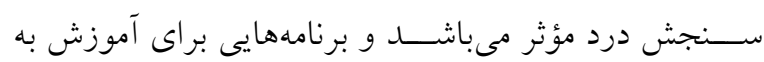

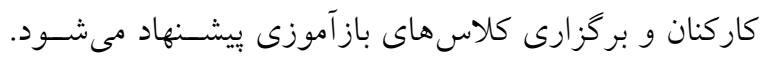
همجنين جهت اسـتفاده از ابزارهاى ســنش درد در كنترل

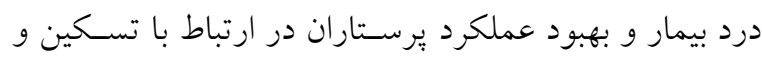

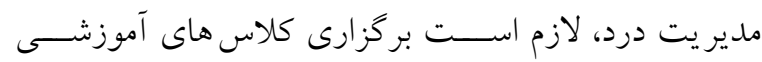

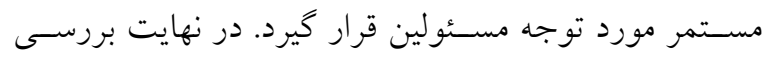
مديريت درد توسط يرستاران بخش اورزانس از ديدكاه بيمار

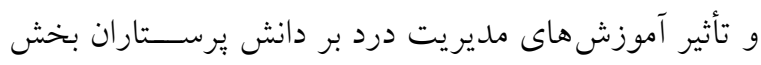
اورزانس يبشنهاد مى گردد.

تعارض منافع: هيج گونه تعارض منافع از سوى نويسندگان كزارش نشده است.

\section{تقدير و تشكر}

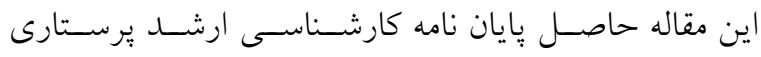

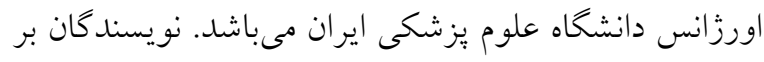

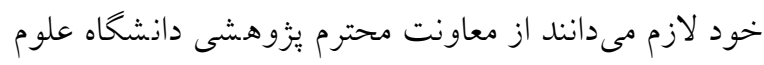

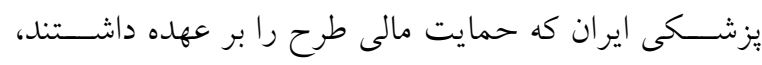
مسئولين دانشكدههاى ير ستارى و مامايى دانشخاههاى علوم يزشكى و خدمات بهداشتى درمانى ايران و يرستاران شركت

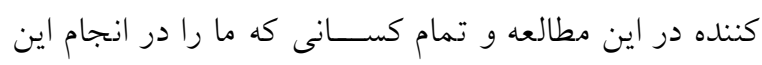
يُزوهش يارى نمودند، تشكر نمايند.
نسبت به اهميت ثبت و كنترل درد دارند به نظر مىرسد كه الزامى بودن تكميل فرم ارزيابى اوليه موجب تكرار و تمرين نحوه تكميل فرم توسط يرستاران شده، به طورى كه فرمها

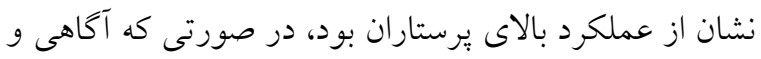
شناخت كافى از ابزارهاى درد و نحوه استفاده از ابزارها را لردا نداشتند. مطالعه فر اهانى و همكاران در يرستاران شاغل در بخشهاى اورزانس، ارتويدى و جراحى دو بيمارستان (عج) كروه شاهد

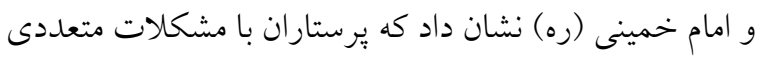
در استفاده از ابزارهاى درد مواجه بودند كه مطابق با مطالعه

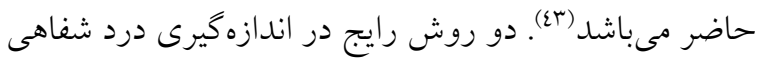
و غير شفاهى، گزارش از خود و مشاهده مستقيم هستند. در

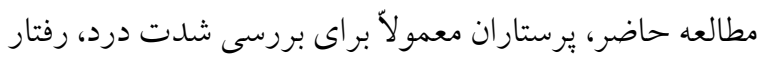
بيمار را مشاهده و اكثريت يرستاران از بيمار در مورد درد سئوال مى كنند. مقياس اندازهيرى درد، موقعيتى اساسى در عملكرد بالينى دارد. مقياسهاى درد بايد براى تبديل كردن

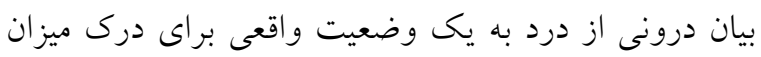
درد بيمار و تشخيص واكنش بيماران به درمان استفاده شوند. در اين يزوهش، مشخص شد كه مقياس سنجش درد در بين

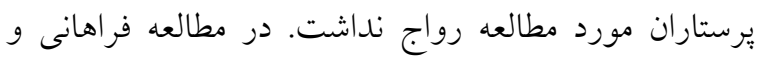

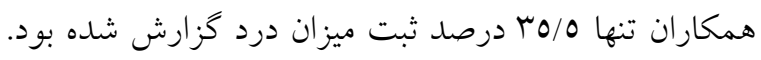
نتايج مطالعه حاضر نيز نشان داد با وجود آن كه يرستاران شركت كننده در مطالعه به صورت خودكزارش دهى بيان داشتند عملكرد و آكاهى خوبى نسبت به اهميت ثبت و كنترل درد دارند ولى آكاهى و شناخت كافى از ابزارهاى درد و نحوه استفاده از ابزارها نداشتند و مطابق با نتايج مطالعات فراهانى

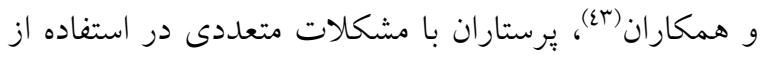

$$
\text { ابزارهاى درد مواجه بودند. }
$$

يكى از محدوديتهاى مطالعه اين بود كه به دليل شلوغى و و درون

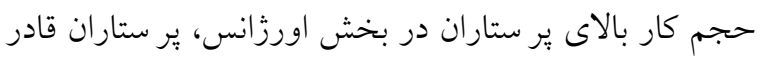




\section{References}

1. Smith B, Ceusters W, Goldberg LJ, Ohrbach R. Towards an ontology of pain. 2011.

2. Erstad BL, Puntillo K, Gilbert HC, Grap MJ, Li D, Medina J, Mularski RA, Pasero C, Varkey B, Sessler CN. Pain management principles in the critically ill. Chest. 2009;135(4):1075-86.

3. Pines JM, Hollander JE. Emergency department crowding is associated with poor care for patients with severe pain. Ann Emergency Med. 2008;51(1):1-5.

4. Khan TH. Job satisfaction in Pakistani anesthesiologists. Anaesth Pain \& Intensive Care. 2011;15(2):93-101.

5. Najafi Ghezeljeh T, Hosseini AF. Attitudinal barriers to effective cancer pain management. Journal of hayat. 2012;18(1):89-101. [Persian]

6. Schug SA, Palmer GM, Scott DA, Halliwell R, Trinca J. Acute pain management: scientific evidence, 2015. Med J Aust. 2016;204(8):315-7.

7. Melotti RM, Dekel BG, Carosi F, Ricchi E, Chiari P, D'Andrea R, Di Nino G. Categories of congruence between inpatient self-reported pain and nurses evaluation. Eur J Pain. 2009;13(9):992-1000.

8. Chang AK, Bijur PE, Napolitano A, Lupow J, Gallagher EJ. Two milligrams iv hydromorphone is efficacious for treating pain but is associated with oxygen desaturation. Journal of Opioid Management. 2009;5(2):75-80.

9. Al-Shaer D, Hill PD, Anderson MA. Nurses' knowledge and attitudes regarding pain assessment and intervention. Medsurg Nursing. 2011;20(1):7.

10. Palmer O, McIver P. Joint Commission of Accreditation of Healthcare Organization accreditation for the office-based oral and maxillofacial surgeon. Dental Clinics of North America. 2008;52(3):641-51.

11. Ramachandran SK, Haider N, Saran KA, Mathis M, Kim J, Morris M, O'Reilly M. Life-threatening critical respiratory events: a retrospective study of postoperative patients found unresponsive during analgesic therapy. J Clinl Anesth. 2011;23(3):207-13.

12. Ucuzal M, Doğan R. Emergency nurses' knowledge, attitude and clinical decision making skills about pain. Int Emergency Nurs. 2015;23(2):75-80.

13. Bennetts S, Campbell-Brophy E, Huckson S, Doherty S, National Health and Medical Research Council's National Institute for Clinical Studies National Emergency Care Pain Management Initiative. Pain management in Australian emergency departments: current practice, enablers, barriers and future directions. Emergency Medicine Australasia. 2012;24(2):136-43..

14. Clarke EB, French B, Bilodeau ML, Capasso VC, Edwards A, Empoliti J. Pain management knowledge, attitudes and clinical practice: the impact of nurses' characteristics and education. Journal of Pain and Symptom Management. 1996;11(1):18-31.

15. Varvani FP, Elhani F, Mohammadi I. Assessing the effects of establishing a nursing commission of pain management on empowering nurses within pain assessment process. International Pain Conference Tehran: Imam Khomeini Hospital ; 2009. [Persian]

16. Smeltzer SC, Bare BG, Hinkle JL, Cheever KH, Townsend MC, Gould B. Brunner and Suddarth's textbook of medicalsurgical nursing $10^{\text {th }}$ ed. Philadelphia: Lipincott Williams \& Wilkins; 2008.

17. Nejat N, Kouhestani HR, Rezaei K. Effect of concept mapping on approach to learning among nursing students. Journal of hayat. 2011;17(2):22-31. [Persian]

18. Gélinas C, Arbour C, Michaud C, Vaillant F, Desjardins S. Implementation of the critical-care pain observation tool on pain assessment/management nursing practices in an intensive care unit with nonverbal critically ill adults: a before and after study. Int J Nurs Stud. 2011;48(12):1495-504.

19. Simon LS. Relieving pain in America: A blueprint for transforming prevention, care, education, and research. Journal of pain \& palliative care pharmacotherapy. 2012;26(2):197-8.

20. World Health Organization. Global strategic directions for strengthening nursing and midwifery 2016-2020.

21. Wang HL, Tsai YF. Nurses' knowledge and barriers regarding pain management in intensive care units. J clin nurs. 2010;19(21-22):3188-96.

22. Herr K. Pain assessment strategies in older patients. The journal of pain. 2011;12(3):S3-13.

23. Ramezani-Badr F, Nasrabadi AN, Yekta ZP, Taleghani F. Strategies and criteria for clinical decision making in critical care nurses: A qualitative study. Journal of Nursing Scholarship. 2009;41(4):351-8. [Persian] 
24. Jarzyna D, Jungquist CR, Pasero C, Willens JS, Nisbet A, Oakes L, Dempsey SJ, Santangelo D, Polomano RC. American Society for Pain Management Nursing guidelines on monitoring for opioidinduced sedation and respiratory depression. Pain Management Nursing. 2011;12(3):118-45.

25. Sakpal T. Sample size estimation in clinical trial. Perspectives in clinical research. 2010;1(2):67-9.

26. Paice JA, Ferrell B. The management of cancer pain. CA: a cancer journal for clinicians. 2011;61(3):157-82.

27. Basak S. Knowledge and attitudes of nurses and their practices regarding post-operative pain management in Bangladesh (Doctoral dissertation, Prince of Songkla University). The $2^{\text {nd }}$ International Conference on Humanities and Social Sciences 2014; Faculty of Liberal Arts, Prince of Songkla University Palliative Care.

28. Ghorbani Moghaddam Z, Jahanpour F, Hajivandi A. Knowledge rattitude and practice of nursing regarding post operative pain management in hospitals affiliated to Bushehr University of Medical Sciences Management. Nurs Vulnerables. 2015;1(1):32-41 [Persian].

29. Modanloo M, Sayed Fatemi N, Bastani F, Peyrovi HA, Behnampour N, Hesam M. Comparison of pain assessment by patients and triage nurses. Iranian J Crit Care Nurs. 2010;4(1):23-8. [Persian]

30. Saadati A, Mirshahi F, Hosseini Shahidi L. The effect of training on nurses' skills improvement in the field of knowledge, control and control of pain. Journal of Urmia Nursing and Midwifery Faculty. 2006;4(1):28-43. [Persian]

31. Ferrell BR, McGuire DB, Donovan MI. Knowledge and beliefs regarding pain in a sample of nursing faculty. J Prof Nurs. 1993;9(2):79-88.

32. McMillan SC, Tittle M, Hagan S, Laughlin J, Tabler RE. Knowledge and attitudes of nurses in veterans hospitals about pain management in patients with cancer. InOncology nursing forum 2000;27(9):1415-23.

33. Aflatoonian MR, Rafati F. The survey of nurses, knowledge and attitude towards pain management in Jiroft University of medical sciences. Anesthesiology and Pain. 2017;8(2):14-21. [Persian]

34. Noghabi A, Soudagar S, Nazari O. Knowledge, attitude and performance of nurses regarding pain assessment and measurement, Bandar Abbas, Iran. Hormozgan Medical Journal. 2012;16(5):403-13. [Persian]

35. Issa MR, Awajeh AM, Khraisat FS. Knowledge and attitude about pain and pain management among critical care nurses in a tertiary hospital. J Intensive Crit Care. 2017;3(1).

36. Latchman J. Improving pain management at the nursing education level: evaluating knowledge and attitudes. J Adv Pract Oncol. 2014;5(1):10-6.

37. Noghabi A, Soudagar S, Nazari O. Knowledge, attitude and performance of nurses regarding pain assessment and measurement, Bandar Abbas, Iran. Hormozgan Medical Journal. 2012;16(5):403-13. [Persian]

38. Enskär K, Ljusegren G, Berglund G, Eaton N, Harding R, Mokoena J, Chauke M, Moleki M. Attitudes to and knowledge about pain and pain management, of nurses working with children with cancer: A comparative study between UK, South Africa and Sweden. J Res Nurs. 2007;12(5):501-15.

39. Gunningberg L, Idvall E. The quality of postoperative pain management from the perspectives of patients, nurses and patient records. J Nurs Manag. 2007;15(7):756-66.

40. Ghorbani Moghaddam Z, Jahanpour F, Hajivandi A. Knowledge rattitude and practice of nursing regarding post operative pain management in hospitals affiliated to Bushehr University of Medical Sciences Management. Nurs Vulnerables. 2015;1(1):32-41. [Persian]

41. Alavi A, Namnabati M, Abdeyzadeh Z, Parvin N, Akbari N, Samipoor V, Deris F. Pediatric pain management by nurses in educational hospitals of Shahrekord in 12006. Journal of Shahrekord Uuniversity of Medical Sciences. 2008;10:1-11. [Persian]

42. Alzghoul BI, Abdullah NA. Pain management practices by nurses: an application of the knowledge, attitude and practices (KAP) model. Global Journal of Health Science. 2016;8(6):154.

43. Varvani Farahani P, Alhani F. Studying the effect of establishing nursing pain commission on using pain scale tools on pediatrics. InInternational Pain Conference. Tehran: Imam Khomeini Hospital 2007. 